\title{
Analysis and strengthening of carpentry joints
}

\author{
Jorge M. Branco \\ Assistant Professor \\ ISISE, Dept. Civil Eng., University of Minho \\ Guimarães, Portugal \\ Thierry Descamps \\ Assistant Professor \\ URBAINE, Dept. Structural Mech. and Civil Eng., University of Mons \\ Mons, Belgium
}

\section{Introduction}

Joints play a major role in the structural behaviour of old timber frames [1]. Current standards mainly focus on modern dowel-type joints and usually provide little guidance (with the exception of German and Swiss NAs) to designers regarding traditional joints. With few exceptions, see e.g. [2], [3], [4], most of the research undertaken today is mainly focused on the reinforcement of dowel-type connections. When considering old carpentry joints, it is neither realistic nor useful to try to describe the behaviour of each and every type of joint. The discussion here is not an extra attempt to classify or compare joint configurations [5], [6], [7]. Despite the existence of some classification rules which define different types of carpentry joints, their applicability becomes difficult. This is due to the differences in the way joints are fashioned depending, on the geographical location and their age. In view of this, it is mandatory to check the relevance of the calculations as a first step. This first step, to, is mandatory. A limited number of carpentry joints, along with some calculation rules and possible strengthening techniques are presented here.

\section{Timber frameworks and carpentry connections}

Timber frameworks are one of the most important and widespread types of timber structures. Their configurations and joints are usually complex and testify to a high-level of craftsmanship and a good understanding of the structural behaviour that has resulted from a long evolutionary process of trial and error. A simplified analysis of (old) timber frameworks, considering only plane parts of the system, is often hard to realize. Nowadays, a considerable number of timber structures require structural intervention due to material decay, improper maintenance of the structure, faulty design or construction, lack of reasonable care in handling of the wood, accidental actions or change of use. While the assessment of old timber structures is complex, it is an essential precursor to the design of the reinforcement of the joints. Owing to a lack of knowledge or time, the species and/or grade assumed are often an overly conservative estimate which can lead to unnecessary replacement, repair and retrofit decisions along with associated superfluous project costs.

For the design of the reinforcement of old timber structures or joints, the first step is to understand fully how the structure and the joints work. Old timber structures are usually highly statically indeterminate structures. This means that loads applied to the structure have different pathways to reach the supports. Resolving the indeterminate system involves looking for additional equations 
that actually express the relative stiffness of all those pathways. To illustrate how the differential stiffness of elements, joints or supports may influence the behaviour of the structure, a simple collar-braced roof is presented in Fig. 1. In the absence of buttressed walls, under vertical loads, the collar (or the tie-beam) is under tension because it prevents the roof from spreading. If buttressed walls restrain the feet of the rafters, the collar is in compression. The only difference between these situations is the horizontal stiffness of the supports (zero or infinite). The mass of the walls to resist the outward thrust is not the only influencing factor. Most of the time, principal rafters are connected to wall plates that have to be stiff enough to act as a beam in the horizontal plane spanning between two fixed ends in the walls. If the rafters are notched, for example, with birdsmouth joints, over the plate at the top, the roof can be hung from the ridge purlin, depending on the stiffness of the wall plate. The stiffness determines the ability of the wall plate to act as an additional support. This is valid for most types of carpentry joints as they usually are statically indeterminate. In conclusion, when working on old carpentry joints, it could be useful, when possible, to look at the joint as an assembly of equivalent springs. This model allows a better understanding of how the joints behave and deform and determines where the major stresses will occur. This could help to avoid incorrect positioning of the reinforcement and thereby circumvent poor design.

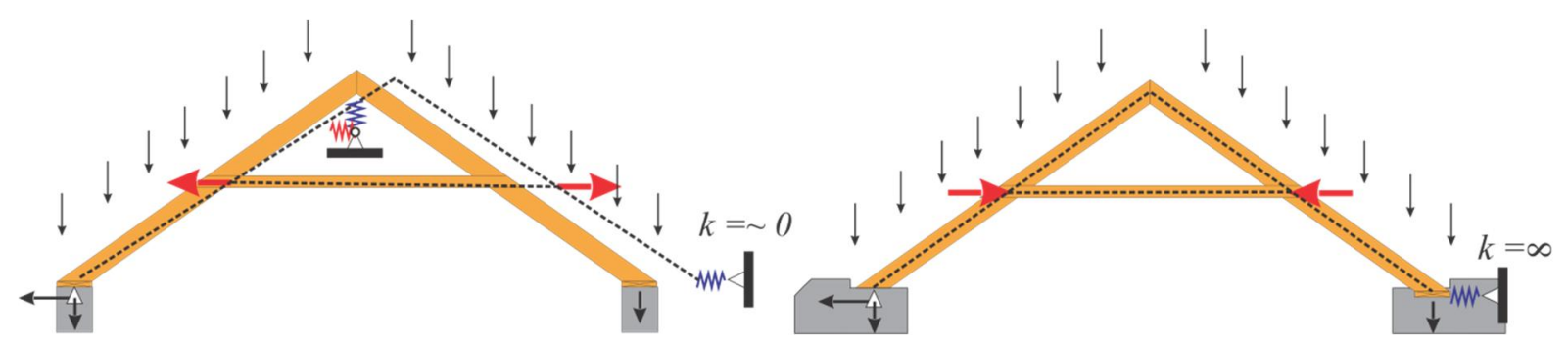

Fig. 1-Collar-braced roof.

The main challenges for the structural assessment of carpentry joints are [8]:

- Stiffness and strength of joints depend on the type of loading. As an illustration, the rotational stiffness of a joint is mostly different under positive and negative bending. Moreover, within most joints there is an interaction between the different pathways in which the forces are transferred in terms of stiffness and strength. This interaction should be considered to define the mechanical behaviour of the connection.

- Despite most current standards not declaring any rules for the assessment of the material strength under combined stresses, their appearance in carpentry joints is inevitable.

- The design of traditional joints essentially involves a check of the contact pressure between the assembled elements. It is not easy to calculate the value of contact pressure in the following situations: unknown contact surfaces and non-uniform stress distributions (because of nonuniform elastic support due to local defects like knots for example). The values of compressive strength of timber are different in the direction parallel and perpendicular to the grain. In order to calculate the strength at any intermediate value of the load angle to the grain Hankinson's formula which has been presented in many standards, may be used.. SIA 265:2003[9] suggests a different expression that takes into account a reduction because of the difference between the strength of early wood and latewood. In addition, some standards allow enlarging the real 
contact surface by taking into account a so-called effective length [36]. Those slight differences about the definition of the compressive strength at an angle to the grain highlight a lack of knowledge, which fortunately, is not of major importance for compression at angles between $30^{\circ}$ to $60^{\circ}$ (which represent the most common values).

\section{Old carpentry joints}

Common traditional carpentry joints found in old timber frames can be categorized in four main types, according to their arrangement and geometry:

- Tenon and mortise joints: There are countless examples of this type of joint. Tenon joints connect members that usually form an "L" or "T" type configuration. The joint comprises two components: the mortise hole and the tenon tongue. The tenon formed on the end of a member is inserted into a square or rectangular hole cut into the corresponding member. The tenon is cut to fit the mortise hole exactly and usually has shoulders that sit when the joint fully enters the mortise hole. The joint may be pinned or locked into place. In the traditional fashion, the pin hole in the tenon is bored a little closer to the shoulder than in the mortise and the pin pulls the joint together very tightly. This kind of joint is mainly used when the adjoining pieces connect at an angle between $45^{\circ}$ to $90^{\circ}$. When the angle between the two jointed elements is different from $90^{\circ}$, the nose of the tenon can be cut off and is called a skewed tenon (see Fig. $3 a \& 6 a)$.
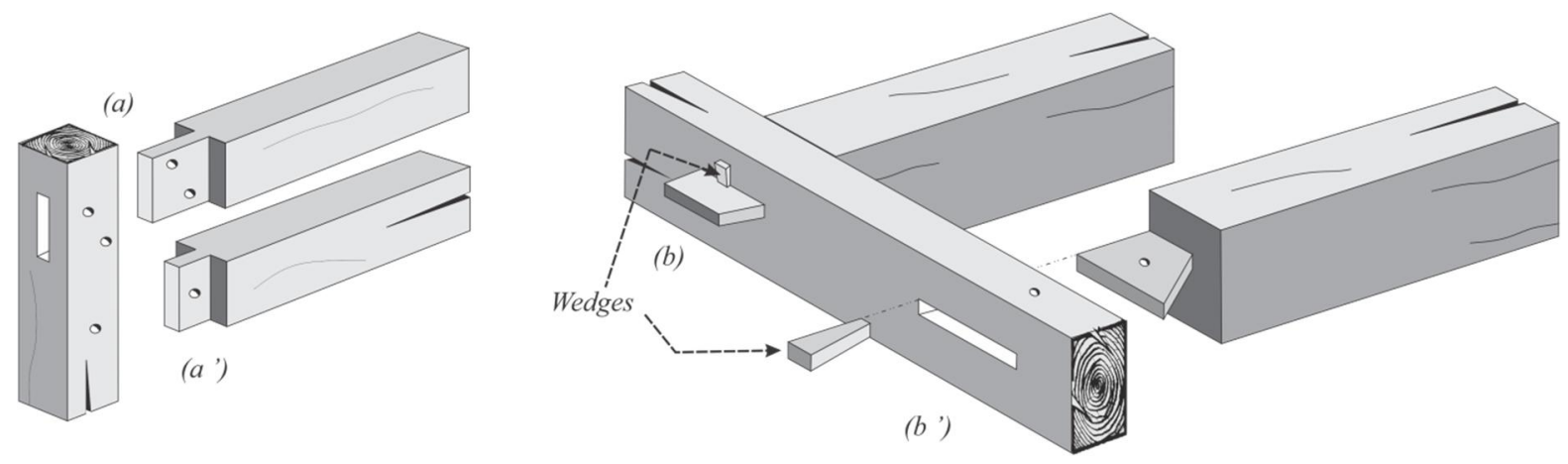

Fig. 2 - (a) Through pinned mortise and tenon ( $\left.a^{\prime}\right)$ blind pinned mortise and tenon (blind means not going all the way through). (b) Through tenon with outside wedges (flatwise bending of the tenon ( $b$ ') wedged and pinned dovetail through mortise and tenon.

- Notched joints: This kind of joint is linked to the development of king post and king post-like frames. In order to work successfully, these frames need appropriate joinery at a multitude of locations. A notch is a "V" shaped groove generally perpendicular to the length of the beam, as seen in Fig. 3. Examples where notched joints are used include cases where secure footing is required for the toe of a rafter (or strut) or between the rafter and the king-post. A tenon can be added to the notched joint to essentially keep all the beams coplanar but the notch is what creates the strength of the joint (because it is stiffer than the tenon). 

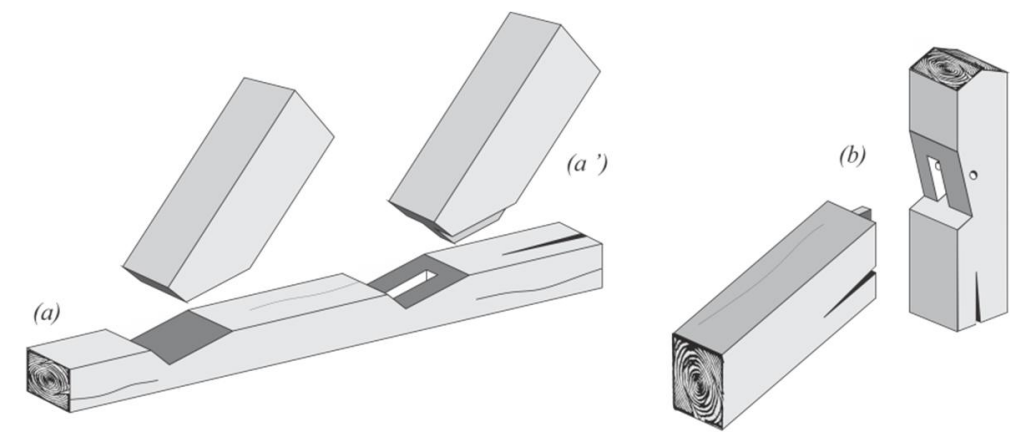

Fig. 3 - (a) Notched joint between main rafters and tie-beam.(a') A skewed tenon may be used to help in keeping all timber pieces co-planar. (b) Peak joint with a notched joint (main rafters and post).

- Lap joints: In a full lap joint, no material is removed from either of the members to be joined, resulting in a joint whose thickness equals the combined thickness of the two members. The members are held in place by a pin (Fig. 4a). In a half-lap joint, material is removed from each of the members so that the thickness of the resulting joint is the same as that of the thickest member. Most commonly, in half-lap joints, the members are of the same thickness and half the thickness of each is removed. The cogged half-lap joint is a half-lap with additional cogs. The dovetail-lap joint (named after the shape of the tenon being similar to the tail of a dove) is another way to fashion the joint in an attempt to reinforce its tensile strength (Fig. 4c).
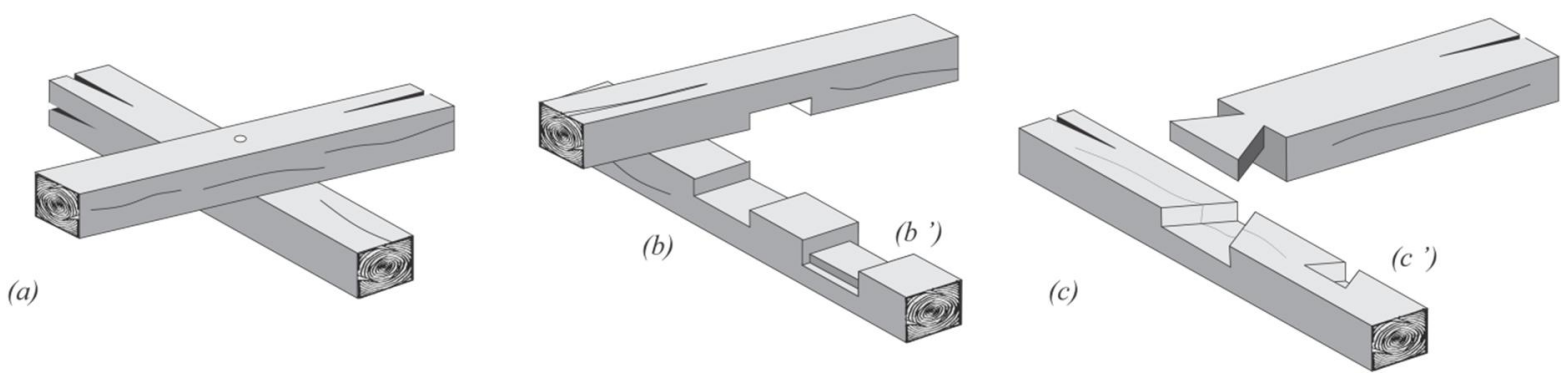

Fig. 4 - (a) Full lap join (pinned). (b) Half-lap joint. (b') Cogged half-lap joint. (c)Through dovetailed lap joint or (c') wedged dovetailed lap joint if ever the dovetail is embedded in the member.

- Scarf joints: Scarf joints (and splice joints), shown in Fig. 5, allow the joining (splicing) of two members end to end [10], [11]. They are mainly used when the material being joined is not available in the length required. This technique is recognised as being the strongest form of unglued member lengthening [12].The halved-scarf joint is a lap whose surfaces are parallel with the members. It is similar to a half-lap joint with co-axial members. The scarf joint is simply a pair of complementary straight sloping cuts secured to each other with pins (also called pegs). Another type of scarf joint is known as the Trait-de-Jupiter or Bolt of lightning, in view of its resemblance to lightning. It is more efficient in the presence of a key (or several keys, depending on the number of indentations - see Fig. 23d) made of hardwood to improve contact and to simplify fabrication. From a mechanical point of view, it is an excellent scarf, 
since the driving of its key separates the twin-tables with a primary mechanical force and closes the under-squinted butts with enormous pressure.
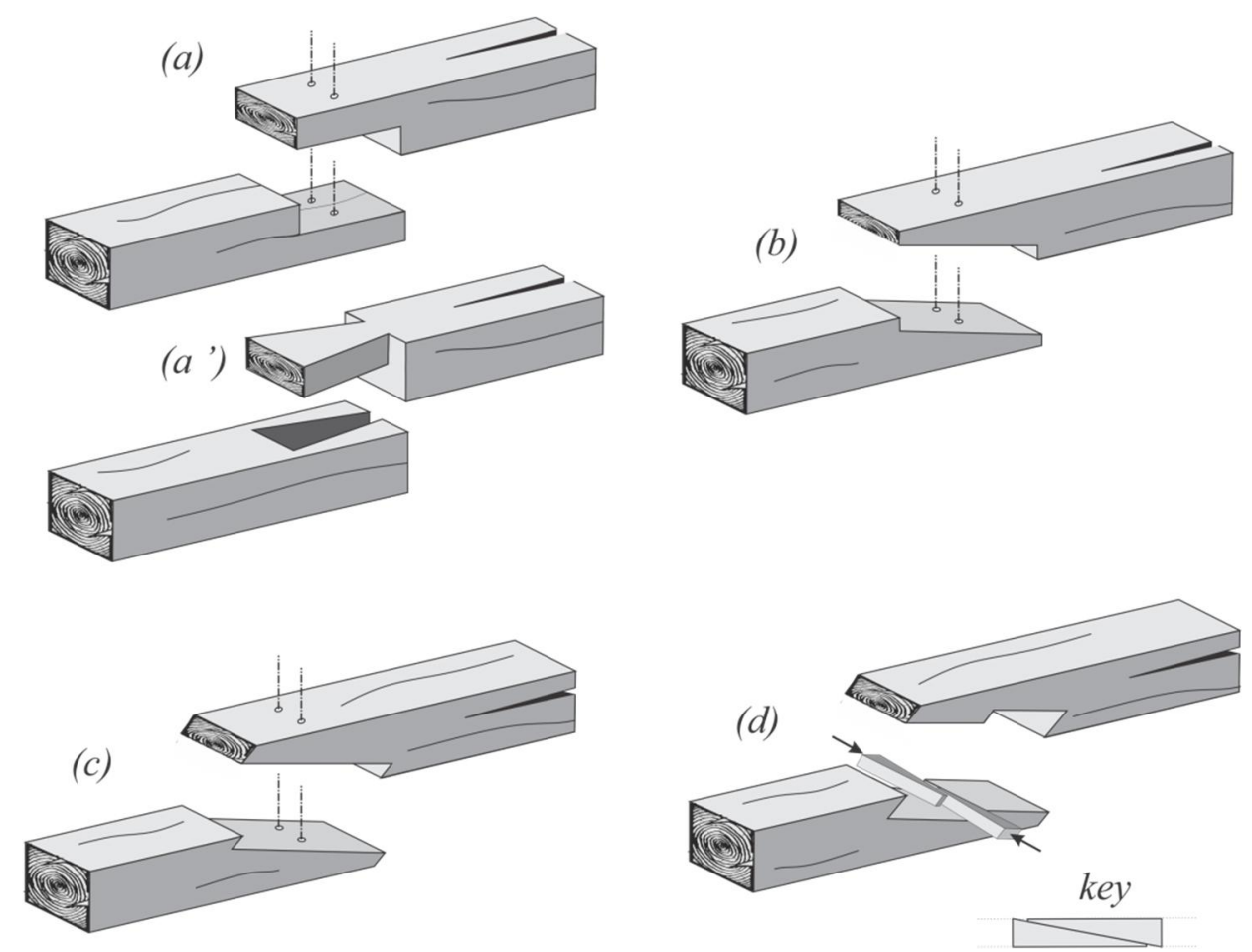

Fig. 5 - (a) Common and simplest halved-scarf joint (or half-lap splice joint). (a')A lapped dovetail scarf joint is a half-lapped joint in which the lapped portions are shaped like a dovetail joint. (b)Scarf joint. (c)Scarf joint with under-squinted ends. (d) Trait de Jupiter: particular scarf joint with wedges (key).

\section{Joint stiffness}

Numerous examples demonstrate the excellent performance of old timber constructions during earthquakes or exceptional wind loads. The reason why they are still standing is not only due to their robustness (highly statically indeterminate structures), but also due to the semi-rigid and ductile behaviour of their joints, which allow for the dissipation of energy. Also, thanks to its loadredistribution process, the beams and joints are able to maintain the capacity of the whole structure in spite of any partial damages.

According to common standards, such as Eurocode 5 [36], the rigidity of elements and joints as well as the eccentricities of the joints have to be taken into account for the computation of the internal forces. However, in order to simplify the analysis, joints are usually designed by assuming an ideally pinned (or rigid) behaviour [13]. It is quite obvious that the assumption of pinned joints is conservative, provided that the joints have enough ductility and are fashioned in a way that their rotation may develop (deformation capacity is sufficient). Nevertheless, in reality most of the carpentry joints are not perfect hinges. Though this is not of major importance for the design of the members, it must be borne in mind that the splitting of timber may occur under low loads (because of component loads perpendicular to the grain). Therefore, in some cases the joints are assumed to be stiff in order to be checked. This is conservative for the joints and results in a 
uneconomic design. Furthermore, carpentry joints usually have a significant moment-resisting capacity even without any strengthening devices. Test results on full-scale notched joints show that this capacity is a function of the compression level in the rafter, the width of the rafter, the friction, the skew angle and the notch depth [3], [14], [15]. Rotational capacity is positively related to the first three parameters.

Undoubtedly, the modelling of the structure taking into account the semi-rigid behaviour of the joints is the best practice:

- A semi-rigid study of a structure suggests taking into account the stiffness of the joints with regard to all the components of the loads (normal, shear and bending). In fact, Descamps et al. [4] have shown that for the computations of the internal forces, the use of the rotational stiffness alone is not enough. Both axial and rotational stiffness have to be introduced in finite element models for an accurate study. The shear stiffness is of less importance.

- Uzielli et al. [16] reported on research work in which different assumptions about the joints in an old timber structure were compared. They found a maximum difference of $20 \%$ between the computed stresses in a semi-rigid model compared to the experimental results, while the difference increased up to $40 \%$ when assuming pinned or rigid joints.

\subsection{Component method}

Design models are available in all standards for estimating the stiffness of dowel-type joints. Unfortunately no information is given about how to get the stiffness of carpentry joints in order to help engineers to gain better results. The component method allows stiffness values to be determined for joints according to their geometrical and mechanical properties. This method, has been used frequently in research on carpentry joints by several authors in the field of steel construction [8], [17], [18], [19], [20]. The problem will be explained by considering a skew tenon joint under an axial load (Fig.6). Since different loads paths are possible (the joint is statically indeterminate), the worst case scenario has been chosen (the mortise is longer than the tenon, which is a common way of fabricating this type of joint).

The component $F_{h}$ is balanced through a uniform contact pressure on the shoulders of the tenon (surface (1) in Fig. 6a). The eccentricity of the resulting forces is not considered here. The load transferred up to the axis of the post (loaded perpendicular to the grain) causes a deformation that can be defined by the stiffness $K_{h}$ :

$K_{h}=\frac{E_{90} \cdot A_{1}}{h / 2}$

where $E_{90}$ is the mean value of the modulus of elasticity perpendicular to the grain, $A_{l}$ is the area of the contact surface ( 1 ) and $L$ is the height of the section of the post. Assuming a gap between the end of the tenon and the post, the component $F_{v}$ is balanced through a uniform contact pressure on the head of the tenon (surface (2) in Fig. 6a). The load transferred to the tenon causes a deformation that can be defined by the stiffness $K_{v}$ :

$K_{v}=\frac{E_{\alpha} \cdot A_{2}}{H / 2}$

where $E_{\alpha}$ is the mean value of the modulus of elasticity at an angle $\alpha$ to the grain, and $A_{2}$ is the area of the contact surface (2).Fig. $6 \mathrm{~b}$ gives the equivalent spring model of the joint under an axial 
load. If $M$ is the moment in the joint and $\theta$ is the rotation into the joint (Fig. 6c), the rotational stiffness of the joint is:

$K_{\text {rot }}=\frac{M}{\theta}$
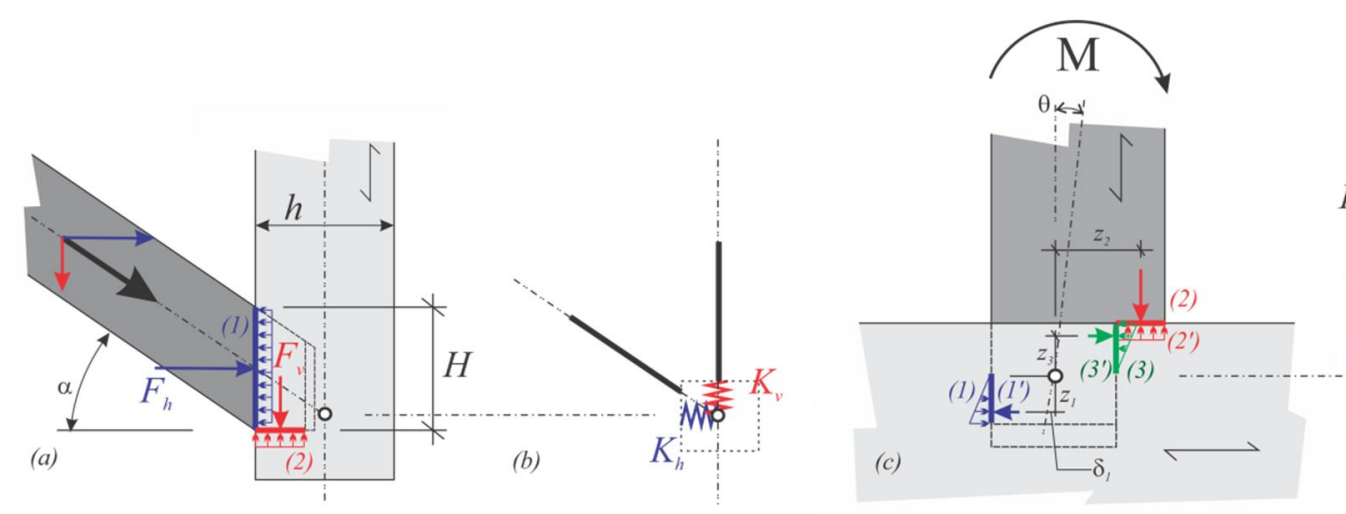

$1 / K_{i, i}=1 / K_{i}+1 / K_{i}$

Fig. 6 - (a) \& (b) Skewed tenon joint under an axial load and the equivalent beam and spring model. (c) \& (d) Tenon joint under bending and the equivalent beam and spring model.

The applied moment is balanced through contact pressures on surfaces (1), (2) and (3). Those pressures can be assumed to be uniform or non-uniform. The effect of friction has not been considered. Each of the contact pressures causes a deformation that can be divided in two components. One component of deformation is caused by the material (i), for example, loaded in parallel to the grain and another component of deformation is caused by material $\left(i^{\prime}\right)$, in contact with (i), for example, loaded perpendicular to the grain. The stiffness $K_{i}$ and $K_{i}$ 'can be defined as proposed by Meisel et al. $K_{i, i}$ is the equivalent stiffness of two springs $K_{i}$ and $K_{i}$, in series (in material (i) and ( $i$ '), respectively) [8]. Drdácký et al. have proposed another definition of the stiffness $K_{i}$ based on a well-known model used to calculate the settlement under a rectangular foundation supported by a semi-infinite half space [17]:

$\frac{1}{K_{i, i^{\prime}}}=\frac{1}{K_{i}}+\frac{1}{K_{i^{\prime}}} \quad$ with $\quad K_{i}=\frac{E_{\alpha, i} \sqrt{A_{i}}}{0.85}$ and $K_{i^{\prime}}=\frac{E_{\alpha, i^{\prime}} \cdot \sqrt{A_{i}}}{0.85}$

If $\delta_{i}$ is the deformation at surface contact (i) and (i'), Fig. 6c:

$M=\sum_{i} F_{i} \cdot Z_{i}=\sum_{i}\left(K_{i, i} \cdot \delta_{i}\right) \cdot Z_{i}$

For small displacements, such as the surface contact (1):

$\operatorname{tg} \theta=\theta=\frac{\delta_{1}}{z_{1}} \Rightarrow \delta_{1}=z_{1} \cdot \theta \quad \Rightarrow \quad M=\theta \sum_{i}\left(K_{i, i} \cdot Z_{i}^{2}\right)$

Finally, the rotational stiffness is equal to:

$K_{\text {rot }}=\frac{M}{\theta}=\frac{\theta \sum_{i}\left(K_{i} \cdot Z_{i}^{2}\right)}{\theta}=\sum_{i}\left(K_{i, i} \cdot Z_{i}^{2}\right)$

Fig. 6d gives the equivalent spring model under bending. Some enhancements of the method, in particular for the definition of the stiffness $K_{i}$, have been proposed by Descamps et al. [4]:

- Definition of a "modified modulus of elasticity" that takes into account the edge effect that appears when surface $(i)$ and $\left(i^{\prime}\right)$ are next to an edge. $C_{\alpha}$ is defined in Fig. 7 where $\lambda$ is the slenderness of the contact area. 


$$
K_{i}=\frac{C_{\alpha} \cdot E_{\alpha, i} \cdot \sqrt{A_{i}}}{0.85} \text { and } K_{i^{\prime}}=\frac{C_{\alpha} \cdot E_{\alpha, i} \cdot \sqrt{A_{i}}}{0.85}
$$

\begin{tabular}{lrrrr}
\hline$\lambda$ & 1 & 2 & 3 & $>3$ \\
\hline$C \alpha$ (parallel) & 0.65 & 0.4875 & 0.364 & 0.325 \\
$C \alpha$ (perpendicular) & 0.65 & 0.5005 & 0.4355 & 0.39 \\
\hline
\end{tabular}

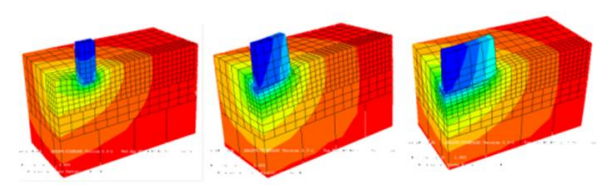

Fig. 7 - Definition of a modified modulus of elasticity.

- New definition of the centre of rotation of the joint. Observations of broken pegs made on real-size tests suggest that the peg is not the centre of rotation of the connection. The assumption has been made that the common position of the centre of rotation corresponds to a minimum of the bending stiffness of the joint (iterative procedure).

Komatsu et al. [19] proposed an enhanced model with a definition of the elastic stiffness $K_{i}$ that takes into account an effective length for the definition of $A_{i}$ (as in Eurocode 5 for the check of compression perpendicular to the grain). They have also proposed a definition of the stiffness in the post yielding range. Chang et al. have proposed some enhancements to this model, in particular to take into account initial gaps and slips [20]. Comparisons with experimentation have demonstrated that the enhanced model achieves good results not only for the initial stiffness of the joints with gaps, but also for the initial slip stage which should be regarded as a pin connection in the early stages.

The component method can be applied to other types of carpentry joints. Researchers have concentrated its use on tenon [18], [19], [20] and lap joints [21], but its application to notched joints is also possible.

\section{Evaluation and reinforcement of carpentry joints}

Before any intervention, the first step is the assessment of the existing joints in relation to the material, the strength and the stiffness. Proper assessment of the material (decay) with appropriate techniques is obviously of major importance and therefore the study of recent state-of-the-art is highly recommended [\#\#].This survey may lead to the replacement of a portion or the whole member. On the other hand, in the case that the member or joint is kept in service and reinforcement is needed, an accurate assessment of the state of conservation of timber is crucial. In the past, the first action taken by carpenters to strengthen joints was based on precise observations of failure modes encountered in real structures and a good understanding of their weakest points. This led to an improvement in the sketching of the joints and one can say that many carpentry joints are an evolution or a reinforcement of older primary joints. For example, a notched joint with a tenon (see Fig. 3a') can be considered as a "reinforcement" of a tenon joint because the slope of the notch increases the load bearing capacity of the joint. In the past, joints were realised without any metal fasteners such as nails, screws or bolts and their ability to carry the loads was achieved through direct contact and friction. Over the years, various reinforcement techniques such as the use of screws (including self-tapping-screws), metal plates (strips, stirrup...), glued composites (glass or carbon fibres, weft knitted textiles) and glued-in rods or even full injection with fluid adhesives among others have been proposed. It should be noted that special 
attention has to be paid to any solution that consists of wrapping the joint in an airtight textile (risk of decay). Furthermore, for the restoration of historic buildings, all interventions should be reversible; if not completely, they should not limit further interventions. For this reason, the injection with fluid adhesive directly into the joint is not recommended anymore [22]. Dowel-type fasteners have been used occasionally in timber joints, for example, to counteract any out-of-plane displacements which cannot be counteracted by the joint itself. This practice became common in the $19^{\text {th }}$ century with the development of industrial production methods and the manufacture of low cost fasteners. Nowadays, the strengthening may aim to locally reinforce the material in the joint area, for example, to reinforce the timber in shear or tension perpendicular to grain by means of self-tapping-screws or to avoid the detachment of the connected elements (joints that could not carry any tension loads for example) or to modify locally the pathway followed by the loads into the joint. Particularly, in seismic areas, strengthening can prevent loss of capacity and possible separation of contact surfaces due to the decrease of compression forces, and may maintain a suitable structural behaviour [2]. The first step of any reinforcement intervention is of course the definition of a proper model of the joint to assess its strength and stiffness. Models and reinforcement techniques will be discussed for the most common carpentry joints here after.

\section{$5.1 \quad$ Tenon joints}

Tenon joints have a very low stiffness that may cause premature failure of a part or the whole structure caused by large displacements encountered in the joint [2]. The bearing capacity of skewed tenon joints is a function of the angle $\alpha$ of the joint, the length of the tenon and the mortise depth [23], [24], [25]. To check the joint, one may use a simple check on all components of the load that appear on the surfaces as it has been discussed in Section 4.1. Each part (i) or (i') of the surfaces in contact is checked in compression at an angle to the grain. Kock et al. have developed guidelines for design that are suitable for skewed tenon joints, under axial and shear loading [26].

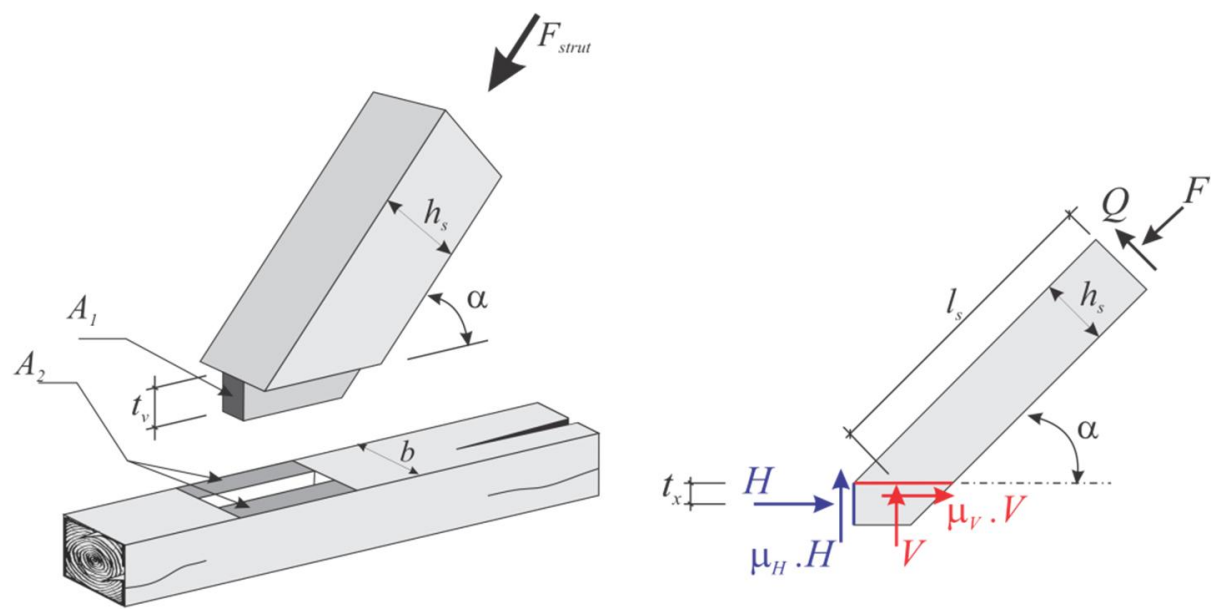

Fig. 8 - Configuration and force mechanism in a skewed tenon joint.

Surfaces $A_{1}$ and $A_{2}$ in contact are presented in Fig 8. $\mu_{H}$ and $\mu_{V}$ are the coefficients of friction of $A_{1}$ and $A_{2}$, respectively, $h_{s}$ and $l_{s}$ are the height and the length of the strut, respectively, and $t_{x}$ is the distance between the bottom surface and the loading point of $H$. The compression loads $H$ and $V$ on $A_{1}$ and $A_{2}$, respectively, are defined as follows: 


$$
\begin{aligned}
& H=F \cdot \cos \alpha+F \cdot m \cdot \sin \alpha-\mu_{V} \cdot V \\
& V=F \cdot \frac{\sin \gamma-\mu_{H} \cdot \cos \gamma}{1-\mu_{H} \cdot \mu_{V}}-F \cdot m \cdot \frac{\cos \gamma+\mu_{H} \cdot \sin \gamma}{1-\mu_{H} \cdot \mu_{V}}
\end{aligned}
$$

where $m$ is the ratio of $Q$ to $F$ :

$m=\frac{Q}{F}=\frac{\left(\frac{\sin \alpha-\mu_{H} \cos \alpha}{1-\mu_{H} \mu_{V}}\right)\left(\frac{h_{S}}{2 \sin \alpha}-\mu_{V} t_{x}\right)+\cos \alpha\left(l_{S} \sin \alpha+t_{x}\right)-\sin \alpha\left(l_{S} \cos \alpha+\frac{h_{S}}{2 \sin \alpha}\right)}{\left(\frac{\cos \alpha-\mu_{H} \sin \alpha}{1-\mu_{H} \mu_{V}}\right)\left(\frac{h_{S}}{2 \sin \alpha}-\mu_{V} t_{x}\right)-\sin \alpha\left(l_{S} \sin \alpha+t_{x}\right)-\cos \alpha\left(l_{S} \cos \alpha+\frac{h_{S}}{2 \sin \alpha}\right)}$

\section{Intervention and reinforcement on tenon joints:}

- Feio et al. have tested full-scale notched and skewed tenon joints under compression in order to assess the local failure in compression and the slipping of the joint [26]. Failure modes observed in the tested joints are damages due to compression in the brace which are localized at the tenon end or distributed along the full contact length. An out-of-plane bulging of wood under the contact length was observed. In some cases, damages in compression associated with shear failure were observed (Fig. 9).
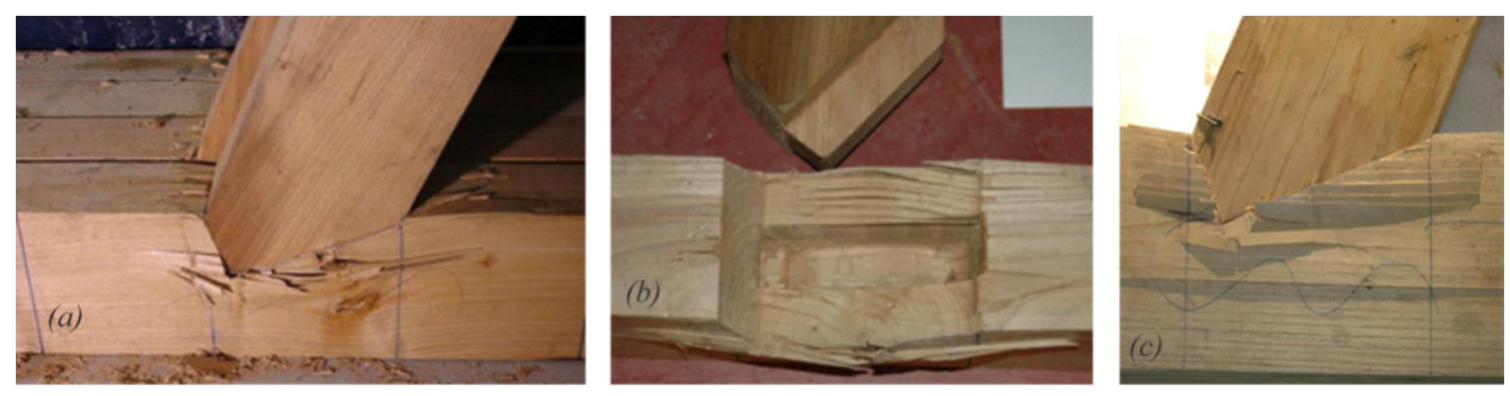

Fig. 9 - Typical experimental failure patterns: (a) joint collapsed in compression, with uniform distribution of damage, (b) joint collapsed in compression, with out-of-plane bulging, and (c) combined failure in compression and shear parallel to the grain at the tenon [27].

When observed on-site, this type of failure mode mainly highlights a poor design of the joint (with contact areas that are too small) or of the structure (unexpected compression forces in one element). No reinforcement can repair damage in compression perpendicular to the grain and the replacement of the element is required most of the time.

- To ensure correct strength and stiffness of the joint, it is important to keep all the surfaces of the joints in contact. In the case of reverse loads or because of high shrinkage of the wood elements, joints may develop gaps. One traditional reinforcement technique consists in placing a wooden wedge to ensure perfect contact between the tenon and the mortise (Fig.10). This wooden wedge should be made of hardwood (for strength and stiffness) and 
its moisture content (MC) should be as close as possible to that of the reinforced wooden elements in order to avoid any shrinkage of the wedge.

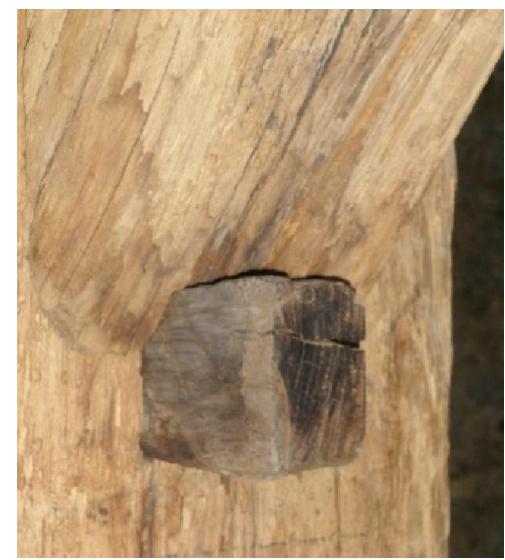

Fig. 10 - Wooden wedge to ensure the contact between the tenon and the mortise.

- Pinned tenon joints also have a very low bearing capacity in tension as only the pin acts. If the element has to be replaced, a traditional reinforcement technique consists in fashioning the joint with a dovetail tenon to increase the strength in tension (Fig. 2b'). If the element remains in service, a binding strip may be used as reinforcement in tension. The strip is screwed onto the edge of the supporting beam to avoid any crack (Fig. 11). For the design of the fastening of the strip, Eurocode 5 expressions for double shear in timber-to-steel connections can be utilized. One may check the tensile stress in steel and the compression perpendicular to the grain under the strip as follow:

$\frac{N}{b . l_{s}} \leq f_{c, 90, d}$ and $\frac{N}{2 \cdot b_{s} \cdot l_{s}} \leq f_{u}$ and $F_{V, R d} \geq N$

where $f_{u}$ is the tensile strength of steel and $F_{V, R d}$ is the shear strength of the fastener. To avoid any tensile forces in the element, a steel wire may be used as presented in Fig. 11b. If broken pins are observed, replacing the wooden pins by steel ones is not suitable as it will probably just cause troubles in the tenon (to be checked).
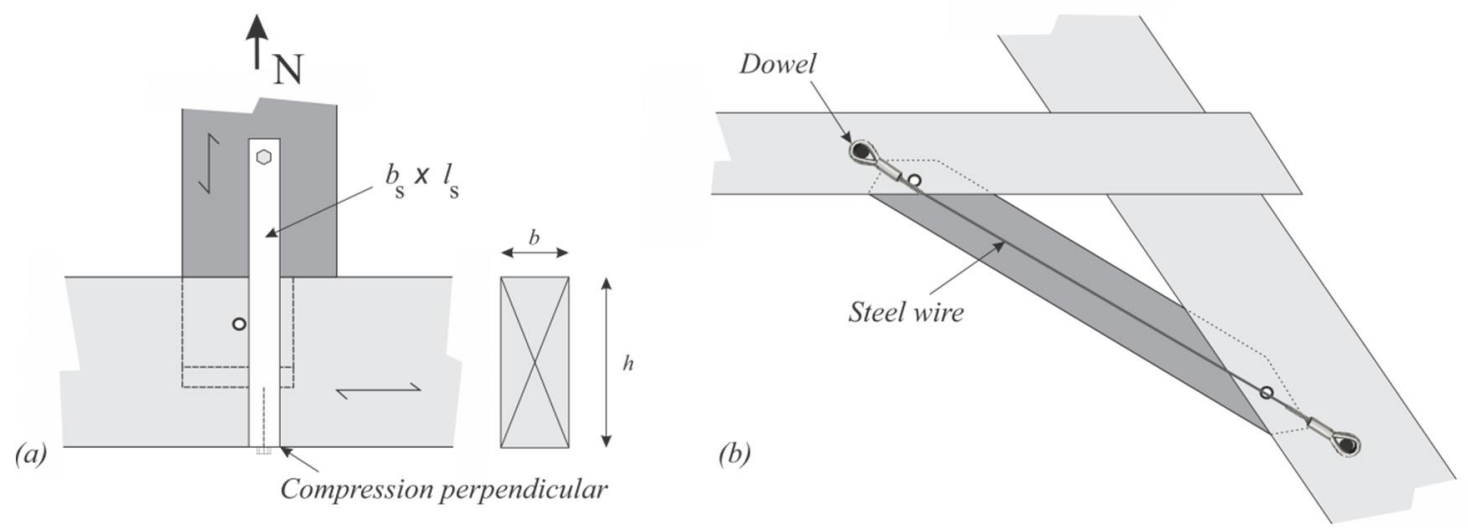

Fig. 11 - Reinforcement of a tenon joint in tension. 


\subsection{Notched joints}

In a notched joint, the slope of the notch should minimize the angle between the stresses and the grain direction for both connected elements, hence increasing the crushing resistance of the joint.

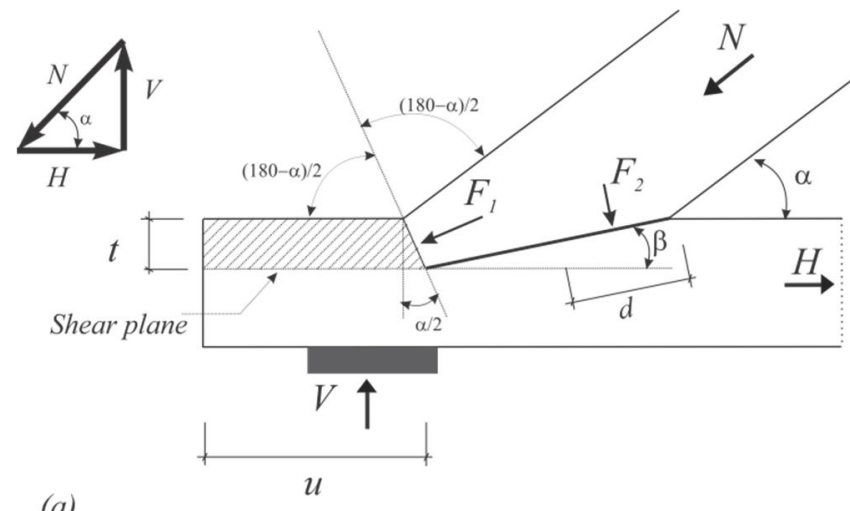

(a)

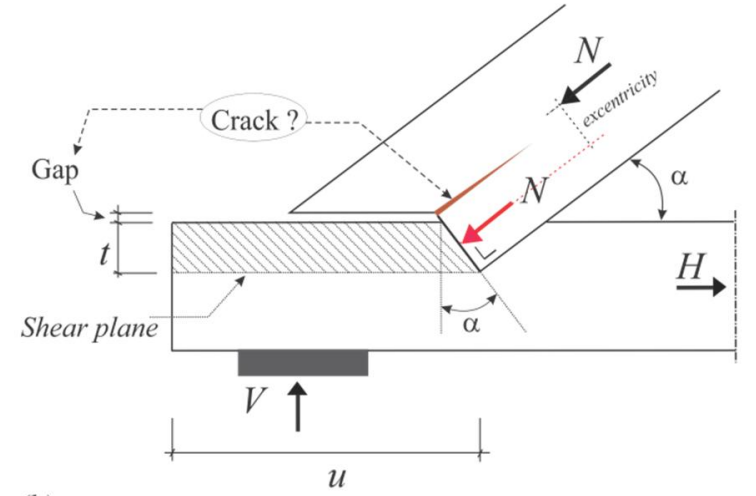

(b)

Fig. 12 - Force mechanisms in a notched joint (tie beam and rafter for example) with the contact surface at the front (a) or at the rear (b)

Based on simple geometric considerations, it is possible to demonstrate that the ideal configuration of the notched joint is the one reported in Fig. 12a, where the angle of the notch is half of the angle $\left(180^{\circ}-\alpha\right)$. According to Götz et al [28] and German and Italian standards [29], [30], the depth of the notch, $t_{v}$, should not exceed $h / 4$ for $\alpha \leq 50^{\circ}$ and $h / 6$ for $\alpha>60^{\circ}$ (linear interpolation between those values is proposed). Friction forces and geometric imperfections are not considered. Based on these assumptions, the axial force is easily resolved into two component forces $F_{l}$ and $F_{2}$ perpendicular to the two surfaces of the notch (Figure 12a):

$$
\begin{aligned}
& F_{1}=N \cdot \cos \frac{\alpha}{2}-N \cdot \sin \frac{\alpha}{2} \cdot \tan \left(\frac{\alpha}{2}-\beta\right)<N \cdot \cos \frac{\alpha}{2} \\
& F_{2}=\frac{N \cdot \sin \frac{\alpha}{2}}{\cos \left(\frac{\alpha}{2}-\beta\right)}
\end{aligned}
$$

If $b$ is the width of the timber elements, the compression at an angle to the grain direction on the notch and the shear in the frontal shear plane must be checked:

$$
\begin{aligned}
& \tau=\frac{N \cdot \cos \alpha}{b \cdot u} \leq f_{v} \\
& \sigma_{c}=\frac{N \cdot \cos ^{2}\left(\frac{\alpha}{2}\right)}{b \cdot t} \leq f_{c, \frac{\alpha}{2}}
\end{aligned}
$$

For the rear face under compression:

$$
\sigma_{c}=\frac{F_{2}}{b \cdot d} \leq f_{c, 90-\beta}
$$


where $d$ is the length of the rear compressed surface of the notch. This last verification, which is often neglected, can be of importance because of the risk of high stresses on a surface of limited length. Parisi et al. proposed the following empirical rule to calculate $d[2]$ :

$d \equiv\left(\frac{1}{5}-\frac{1}{3}\right) \frac{t}{\sin \beta}$

It is important to draw attention to the assumptions that have been made. Assuming that there is no friction is quite far from reality. Friction may increase the stresses in the shear surface. The check of shear stresses in front of the notch must be done with caution. In consequence of the fragile nature of the shear failure, for instance, some standards on earthquake resistant structures (e.g.[31]) adopted a higher partial factor for material properties (equal to 1,3) in the quantification of $f_{v, d}$.

The notched joint with the contact surface at the rear aims to increase the shear strength of the joints by increasing the shear surface in front of the notch (Fig.11b). To fashion the joint easily, a notch is made perpendicular to the direction of one of the two members. In this case the joint strength decreases because the slope of the notch does not minimize the angle between the stresses and the grain direction for both connected elements anymore. The compression at an angle to the grain direction at the notch and the shear in the frontal shear plane must be checked:

$\tau=\frac{N \cdot \cos \alpha}{b \cdot u} \leq f_{v}$

$\tau=\frac{N \cdot \cos \alpha}{b \cdot t} \leq f_{c, \alpha}$

Owing to the eccentricity between the load $F$ and the contact surface, the joint will turn (open) and a crack can appear. Even with a gap of 1 or $2 \mathrm{~mm}$ between the two connected members which prevent the nose bearing of the rafter, it is almost impossible to avoid the splitting of the rafter.

Double step joints, whose geometry results from the sum of two different single steps joints, increase the shear surface without a major risk of splitting (Fig. 13). To fashion the joint, the rear notch must be deeper than the one at the front. To ensure that the joint works well, precision is required so that all surfaces will be in contact (which is not easy to get especially when it is done manually). According to Italian standard: $t_{1} \leq 0,8 . t_{2}$ and $t_{1} \leq t_{2}-10 \mathrm{~mm}$ [11]. Whatever the skew angle of the connection, for a double notched joint, Götz et al. recommends $t_{1} \leq h / 6$ and $\mathrm{t}_{2} \leq \mathrm{h} / 4$ [28], [30].

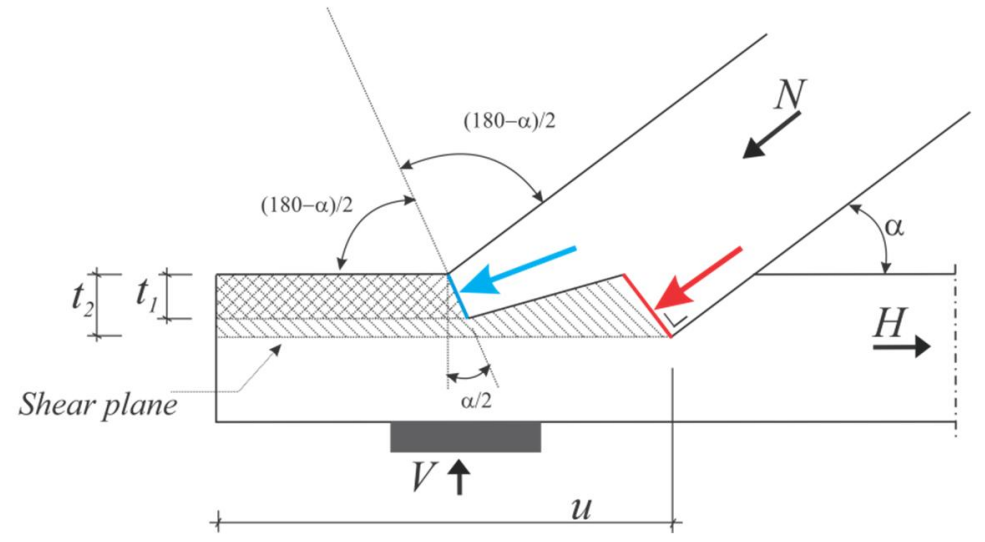

Fig. 13 -Double notched joint. 
Strengthening of notched joint also concerns the friction-based behaviour of the joints in its own plane, preventing the separation of friction surfaces due to the decrease of compression forces (a notched joint has no tensile strength). A series of monotonic and cyclic tests on unstrengthened and strengthened joints has been performed by Branco et al. in order to study the initial behaviour of the connection, as well as its sensitivity to a few parameters [3]. Even without any strengthening devices, notched joints usually have a significant moment-resisting capacity. This capacity depends on the axial compression load in the rafter and on the skew angle [2], [3]. Moreover, it is obvious that the height of the rafter [33], the friction [2], the existence of an additional tenon [27] and the moisture content [15] are also important.

\section{Intervention and reinforcement for notched joints:}

- If the wooden elements do not perfectly match in the notched area (lack of precision in the cutting of the members or because of shrinking), the placement of wooden wedges is recommended to ensure a perfect contact between connected surfaces with a clear increase in the load-carrying capacity of the joint.
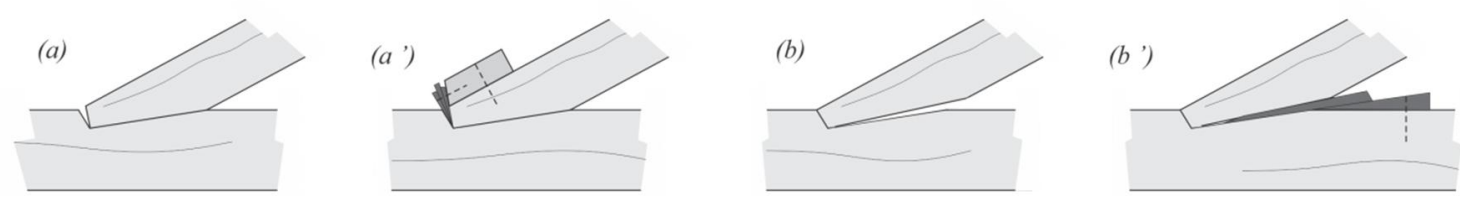

Fig. 14 -Wooden wedges used to ensure a perfect contact between elements. Gaps in the front notch (a) and rear surface (b) and possible use of wedges, ( $\left.a^{\prime}\right)$ and ( $\left.b^{\prime}\right)$, respectively.

- The strengthening of existing notched joints mainly aims to avoid shear failure in the front portion of the notch. Most of the time, an end beam repair is required because of decay and a wooden prosthesis must be used to replace the degraded material (Fig 15). The prosthesis is mechanically jointed to sound wood (or resin). One may use the following check:

$N \cdot \cos \alpha \leq n_{e f} . F_{V, R d}$

where $n_{e f}$ is the effective number of fasteners and $F_{V, R d}$ is their load-carrying capacity[36]. Using inclined fasteners increases the load-carrying capacity of the prosthesis. 

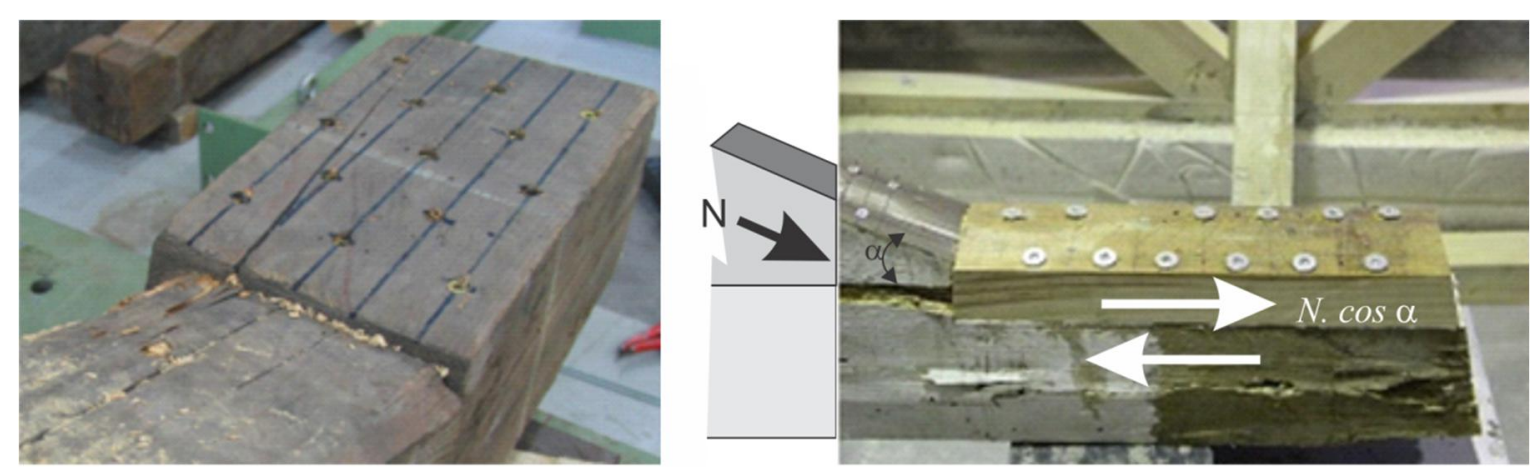

Fig. 15 - Notched joints reinforced to shear stresses in the frontal part of the notch with a screwed prosthesis.

- In times past, binding strips, stirrups and bolts were used in seismic regions to avoid the dismantling of the connected members under reverse loads (Fig 16). When metal elements were used in the original construction of the joints, or, added later, the intervention usually included the substitution of the connectors (nails, bolts, etc.) by new ones and the treatment of the metal.
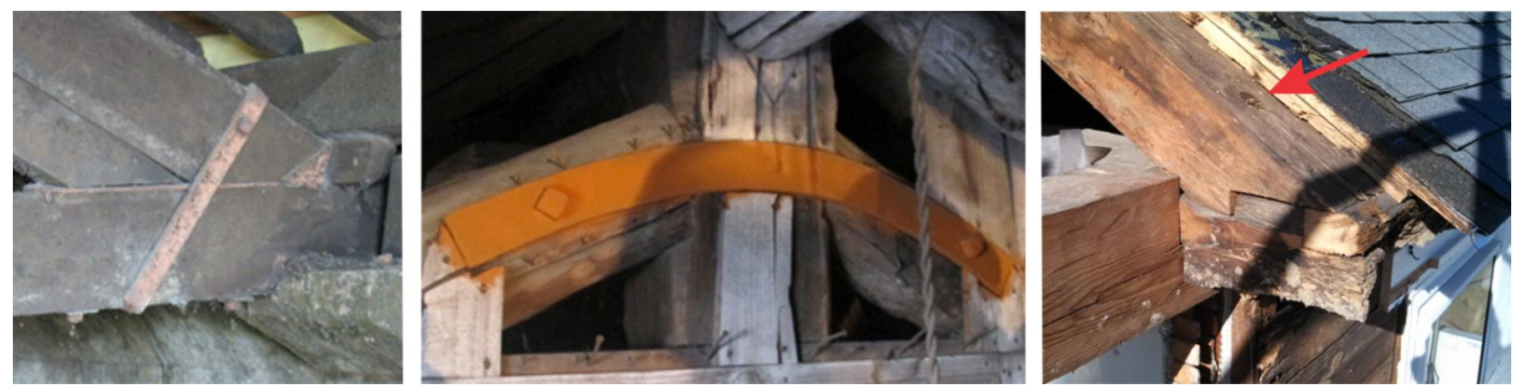

Fig. 16 - Examples of notched joints with metal devices.

The strengthening techniques used presently look to reproduce the old techniques even when using new fasteners like screws and self-tapping screws (see Figure 17). These kinds of interventions affect the stiffness of the joint, which should be checked too.
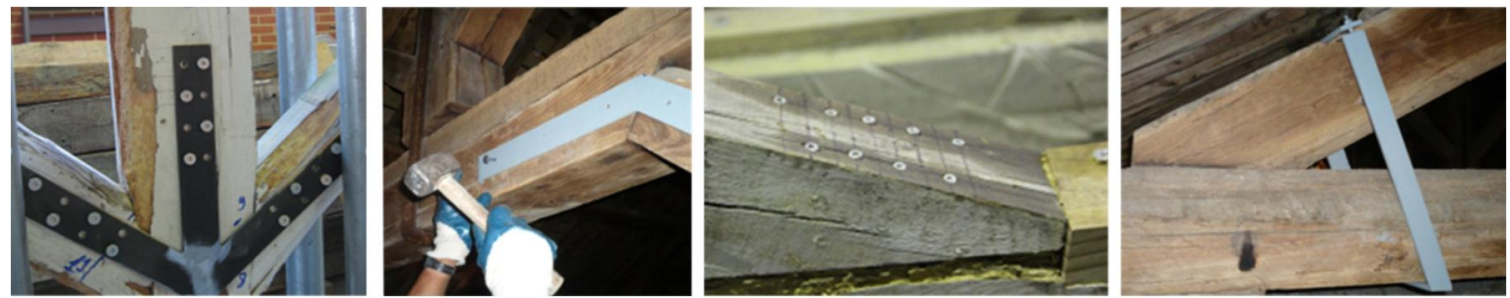

Fig. 17 - Contemporary strengthening interventions on notched joints reproducing old techniques. 
- Strengthened joints with metal devices were tested by Branco et al. under monotonic and cyclic loading. The purpose was to uncover any advantages and drawbacks in the behaviour of the joint and of the strengthening as well as to look at different types of strengthening. The four types of strengthened joints tested are modern implementations of traditional techniques (Fig. 18):
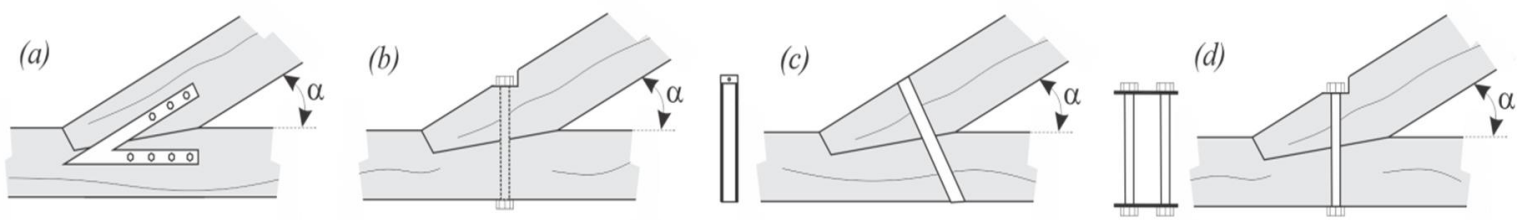

Fig. 18 - Traditional strengthening techniques of notched joints: (a) metal stirrups, (b) internal bolt; (c) binding strip (d) tension ties.

- Metal stirrups placed in pairs on two sides of the joint have been a popular reinforcement in the past. Each stirrup was composed of two steel plates welded in a $\mathrm{V}$-shape and bolted with seven bolts of $10 \mathrm{~mm}$ of diameter. Each prong was $50 \mathrm{~mm}$ wide and $5 \mathrm{~mm}$ thick.

- The steel rod (12mm of diameter) was fixed by a nut at both ends and secured by using a special rectangular-shape washer $\left(70 \times 30 \mathrm{~mm}^{2}\right.$ and $5 \mathrm{~mm}$ thick). The rod was located at mid-joint and mid-width and normal to the axis of the tie beam. A notch has been cut in the rafter to ease the contact between wood and the washer.

- Metal binding strips were also frequently used in the past, particularly to strengthen joints at an angle of $30^{\circ}[33]$. Two updated versions were considered:

- The joint was bound by a steel ribbon $(50 \mathrm{~mm}$ wide, $5 \mathrm{~mm}$ thick) located at midconnection, normal to the tie-beam.

- The joint was bound with two steel plates located in the bottom surface of the tie beam and upper surface of the rafter $\left(40 \times 159 \mathrm{~mm}^{2}, 10 \mathrm{~mm}\right.$ thick $)$ tightened through two rods of $12 \mathrm{~mm}$. One may notice that this solution enables a control of the tightening force during the strengthened lifetime.

All have been analysed for $\alpha=30^{\circ}$ and $\alpha=60^{\circ}$ except the rigid binding strip ( $\alpha=30^{\circ}$ only Fig. 18c). Force-displacement curves under monotonic loading for unstrengthened and strengthened joints (whatever the $\alpha$ values) are presented in Fig. 19. It was observed that all the strengthening techniques used have resulted in improved joint behaviour. 

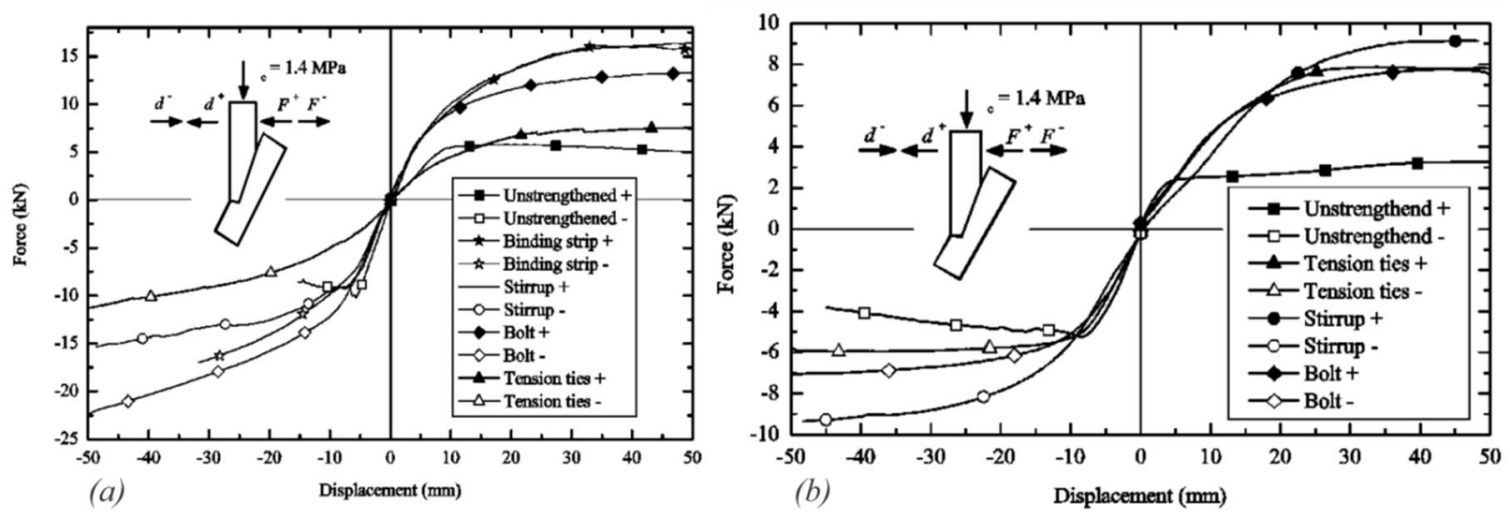

Fig. 19 - Force-displacement curves under monotonic loading for unstrengthened and strengthened connections with $\alpha=30^{\circ}$ (a) and $\alpha=60^{\circ}(\mathrm{b})$

Despite the amount of tests done, results are still insufficient to propose design equations for all the tested configurations and reinforcements. There is still an evident lack of results and scientific data about this topic, which clearly points out the lack of research in this field. However, some interesting observations can be drawn. For $\alpha=30^{\circ}$, one may notice:

- All the strengthening techniques used have increased the stiffness, in particular for the positive loading direction and the maximum load for both directions. One should check if this modification of the stiffness has any consequence on the whole structure.

- Large improvement of the ductility, especially under a negative loading (the reinforced joint does not behave in a brittle way anymore).

- Reinforcement with stirrups and binding strips are similar from the point of view of the maximum load reached. However binding strips have a lower ductility under negative forces.

- Among all strengthening techniques tested, the least efficient regarding both maximum force and stiffness is the solution with the tension ties.

For $\alpha=60^{\circ}$ :

- The behaviour of the unreinforced joint is ductile. Nonetheless, a significant increase of the ductility of the reinforced joint has been observed.

- The same conclusion can be given for the increase in maximum load (whatever be the technique used).

- No significant influence on initial stiffness has been observed.

- The efficiency of the reinforcement is almost the same for all techniques under positive loading. For a negative loading, the metal stirrup is the most efficient technique whereas the solutions with tension ties and bolt are similar.

\subsection{Lap joints}

The pin used in a full lap joint is of major importance as the joint cannot carry any loads without 
it. Based only on the strength of the pin, the efficiency of the full lap joint is of course very low. The half-lap joint is a first improvement of the joint given that it carries the loads by contact in addition to the pin. In the half-lap joint, both the connected elements are half weakened, however the joints may be fashioned differently to avoid weakening the members (one-third of the height instead of a half). As a result the two pieces do not sit flush, which can limit the use of the joint. This configuration is useful when both members bear a larger load. The lap joint presented in Fig. $4 b$ ' (between the half-lap joint and the cogging joint) is configured to increase capacity for both members by adding bearing surfaces. The lower supporting beam has less material removed compared to a half-lap. The side housings provide better support for the upper girder and lessen shear problems [6].

To check the joint, the total load can be resolved into equivalent loads acting on contact surfaces. Each component is checked with regards to the strength in compression at an angle to the grain.

\section{Intervention and reinforcement for lap joints:}

- If the wooden elements do not match perfectly in the notched area (due to lack of precision in the cutting of the members or because of shrinking), the placement of wooden wedges should be recommended to ensure perfect contact and, consequently, the attainment of full load-carrying capacity of the joint.

- If a shear failure is observed in one of the elements, it can be reinforced with fully threaded self-tapping screws (screws are better than bolts in case of shrinkage). Fully threaded screws are required as they have to suspend the lower part of the beam from the upper part the lower part of the beam to the upper part. Incline screws may achieve a better loadcarrying capacity of the reinforced joint than screws screwed perpendicular to the grain direction. To guarantee an efficient reinforcement, the distance $a$ between the screw and the notch should be minimized but with $a \geq 5 d$.
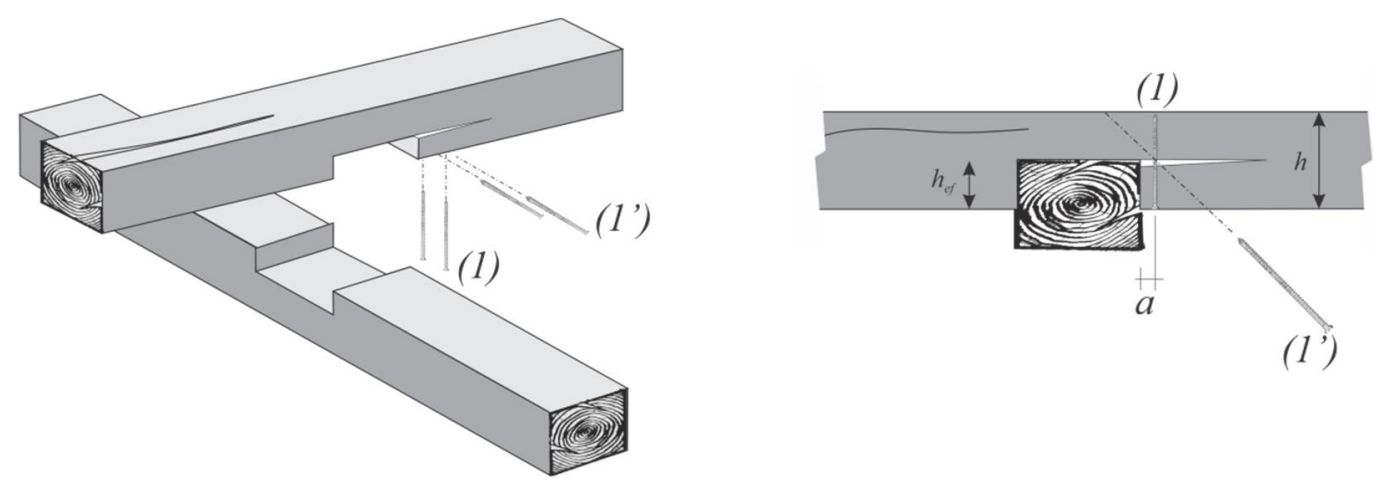

Fig. 20 - Reinforcement in tension perpendicular to grain in lap joints: (1) reinforcement with self-tapping screws perpendicular to the grain. (1') reinforcement with inclined screws.

Design equations developed for notched beams can be used. The design tensile force, $F_{t, 90, d}$ to be carried by the reinforcement, can be determined according to [38]: 
$F_{t, 90, d}=1,3 \cdot V_{d} \cdot\left[3 \cdot(1-\alpha)^{2}-2 \cdot(1-\alpha)^{3}\right]$

Where $V_{d}$ is the design shear force and $\alpha=h_{e f} / h$

- In dovetail-lap joints, the peg keeps all wooden pieces together and prevents the formation of gaps. When a gap occurs, the contact surfaces become smaller and so, the contact pressure becomes larger. One traditional reinforcement technique consisted in the placement of a wooden wedge to ensure perfect contact (see notched joints).

- In dovetail-lap joints loaded in tension, the splitting of timber is a common failure mode. The traditional reinforcement of those joints consists in adding fasteners (bolts, nails, screws, etc.) restoring the shear mechanism provided by the pin (Fig. 21). The design of this strengthening technique is based on the calculation of the shear resistance $F_{V, R k}$ of the new fasteners. This intervention affects the stiffness of the joint (displacement of the centre of rotation). Binding strips or steel wire may also be used (see tenon joints).
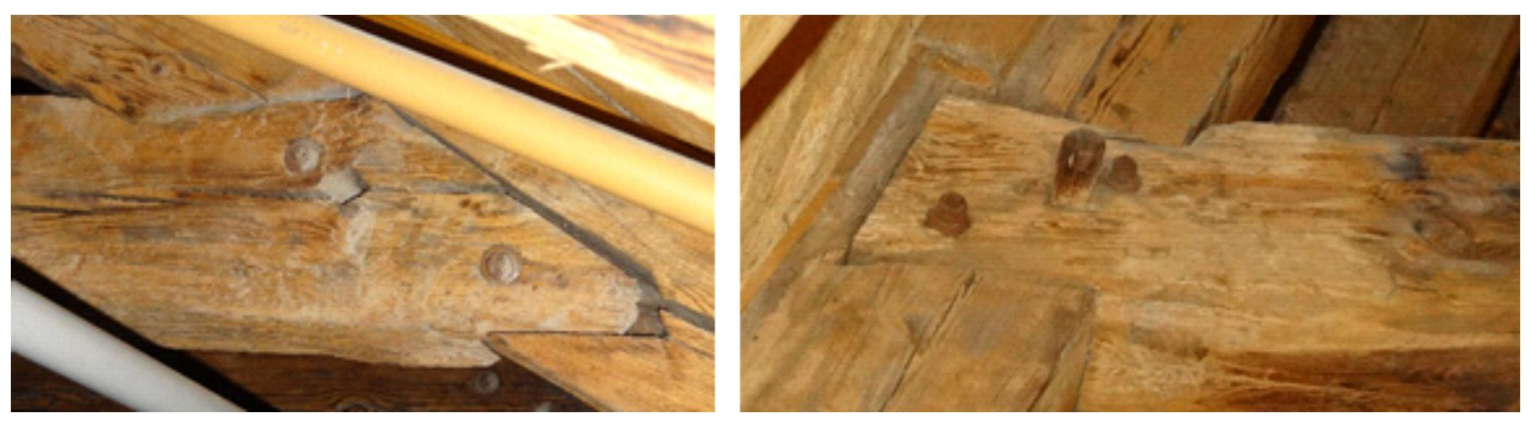

Fig. 21 - Traditional reinforcement of dovetail-lap joints under tension loads by adding wooden dowels

\subsection{Scarf joints}

Two timber members connected using scarf jointing techniques cannot match the strength and stiffness of a single member of the same dimensions. Besides the type of scarf joint, the actual size of the elements, the strength of the wood and other factors have a substantial effect on the assembled member's strength and stiffness. All the different types of existing scarf joints are a proof of all attempts made by carpenters to strengthen the joints and fit particular requirements. For example, the scarf joint (Fig. 5b) is an improvement of the half-scarf joint (Fig. 5a) that works better in shear because less material is removed from each of the members and there is no sharp angle. If the half-lap is horizontal (and loads are vertical, see Fig. 23a), the maximum moment it can carry is one-quarter of the moment of a solid beam, because the half-lap has the width of the beam but one-half of the height. For a vertical half-lap (the scarf is face-halved and loads are vertical too), the width is one half of the solid beam but the height of the half-lap is equal, so the maximum moment it can carry is one-half of what a solid beam will transfer. A study carried out by TRADA suggested that the limiting moment capacity of scarf joints (which behave better in bending than the half-lap scarf) is equal to only a third of the strength of the unjointed beam [35].

For the design, one may check all components of the load that appear on the surfaces in contact. However, it should be noted that very few research campaigns have been conducted on the reinforcement of scarf joints or even on their design. Four types of reinforced scarf joints have been tested by Hirst et al. [11]. The beam sections were 
200x150 mm², all pin holes were $19 \mathrm{~mm}$ in diameter and in keeping with traditional practice, the pin holes on one side of the scarf were offset by $3 \mathrm{~mm}$ with respect to the other side of the joint (tightening the joint when the pins were driven through the joint). Once again, the results are still not sufficient to discuss about the advantages and drawbacks of different techniques or to propose a design equation for reinforced scarf joints.
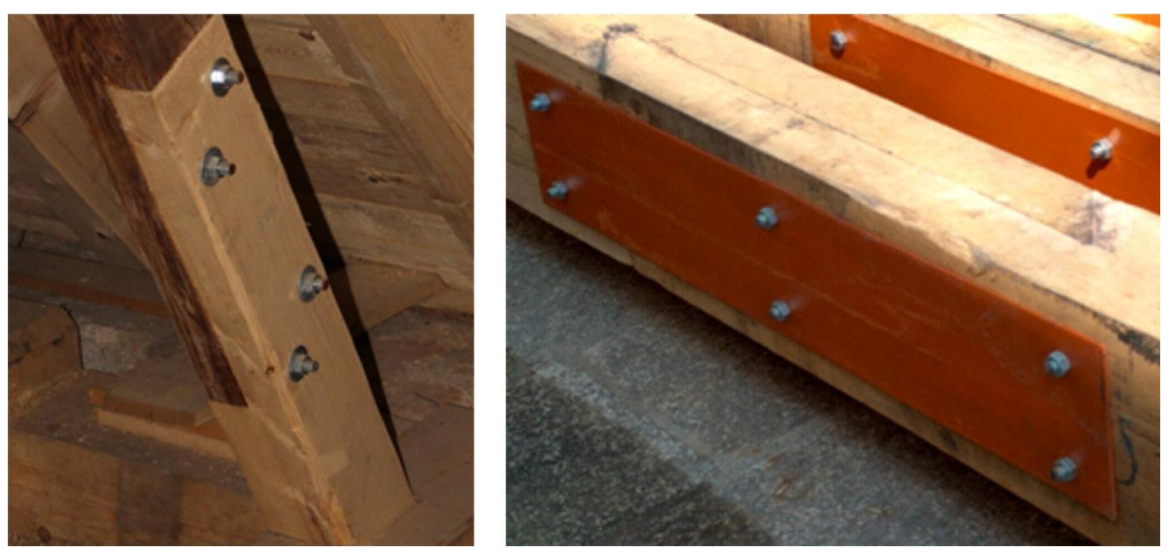

Fig. 22 - Scarf joints reinforced with metal connectors and plates.

\section{Intervention and reinforcement for scarf joints:}

- If the wooden elements do not perfectly match in the notched area (lack of precision in the cutting of the members or because of shrinking), the placement of wooden wedges should be recommended to ensure a perfect contact and hence the achievement of the full loadcarrying capacity of the joint.

- The easiest way to reinforce a scarf joint is achieved by adding metal fasteners (screws or bolts). In ancient times they were made of wood. In case of high loads, lateral metal plates can be added to improve the load-bearing capacity of the joint and to increase the stiffness (that needs to be checked). Both types of reinforcements are used in restoration works (Fig.22).

- Under bending, the rule of thumb that the weak point is the risk of premature splitting of wood is encountered here too (joints cut with right angles are less suitable). From this point of view, scarf joints are better than halved-scarf joints. Self-tapping screws can also be used to strengthen the joint (Fig. 23a). Design equations used for notched beams can be used (see lap joints). Under tension only, reinforcement screws can be driven only in the overlapping area (Fig. 23d). This reinforcement can be checked using Johansen's equations assuming that the tensile load is completely carried by the screws.

- In the case of the Trait-de-Jupiter it is common to add metal connectors passing through the joint depth to reinforce the joint (Fig. 22d). Another solution with glued in rods is presented in Fig 23. 

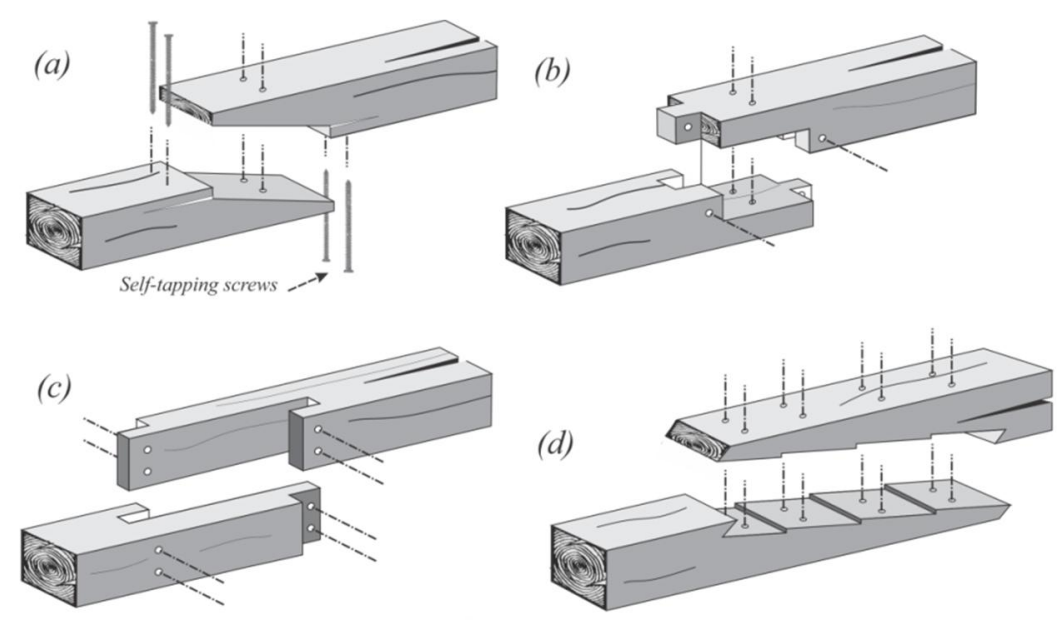

Fig. 23 - (a) Scarf joint reinforcement perpendicular to the grain with self-tapping screws. (b) Reinforcement of bending strength (weak axis) with a cog (half cogged scarf joint). (c)Facehalved scarf joint. (d) Multiple scarf joint with under-squinted ends.
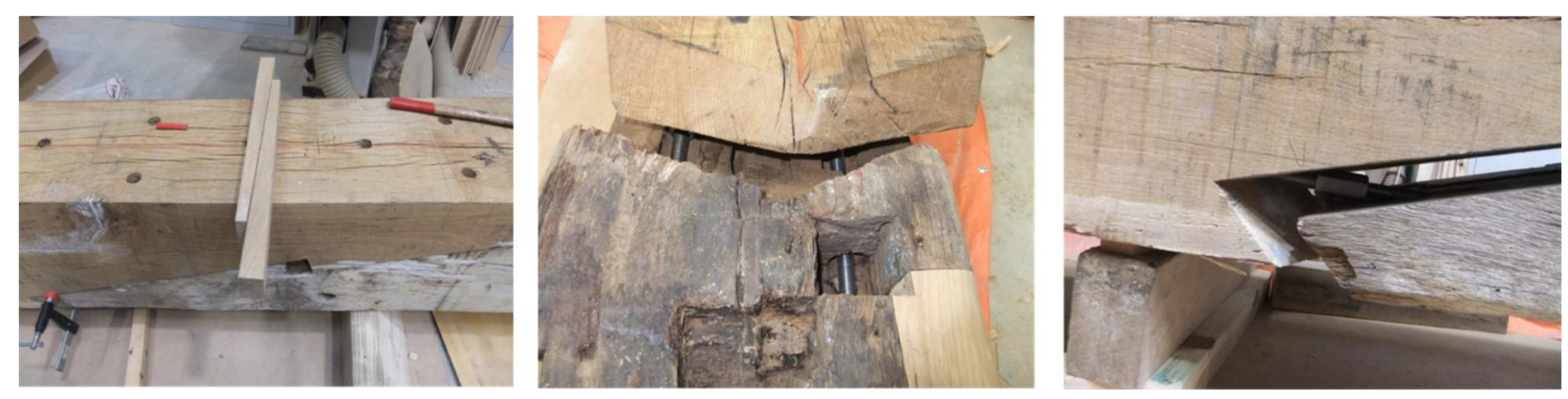

Fig. 24 - Scarf joint reinforced with glued in rods: steel rods are glued in both timber members and connected with a long nut (Credits: Pascal Lemlyn. Restauration du Moulin de l'abbaye de la Paix Dieu, Institut du patrimoine Wallon, Belgique).

\section{Conclusions}

When working on old timber structures, the fact that the structure has stood for decades or centuries without failure may not be sufficient proof of the bearing capacity for the future (new imposed loads etc.). Joints greatly influence the response of the whole structure. Their characterization (the strength, the stiffness and the ability to be reinforced) still remains a big challenge.

The design of traditional joints essentially involves a check of the contact pressure between the assembled elements. Even if seemingly trivial, checks of old carpentry joints still remain a hard task. As an illustration, the slight difference in the definition of the compressive strength (which is of major importance) at an angle to the grain mentioned in different standards, underscore a basic point that has to be clarified anyway by further research and later on by the revision of current standards. Moreover, not only the strength, but also the stiffness of the joint has to be considered as it can influence the force distribution within the structure.

If the decay of timber elements is too large, the replacement is clearly the only solution. If repairs are necessary, specific reliable on-site assessment techniques are required to determine the appropriate level of intervention needed. This point remains very important to evaluate the 
replacement, repair and retrofit solutions along with the associated project costs.

It should be noted that there is still a noticeable lack of scientific results and design rules regarding the reinforcement of old carpentry joints. This clearly points out the lack of research in this field. Unfortunately, this lack of information in addition to difficulties in assessment and definition of grading protocols for old timber elements often lead to unnecessary replacements. Further studies in the area are deemed necessary in order to establish reliable design models, to set detailing rules and to provide recommendations for future rehabilitation or strengthening interventions, among others.

Because of the wide variety of carpentry joint geometries in existence, studying them with an exhaustive approach is neither realistic nor useful. For an accurate study, a good understanding of how the joint works and how the loads are balanced is the key point. As seen in this review, some information about strength, stiffness and reinforcement of common joints exists; even though scientific data is still missing and complementary research is needed. To achieve competency, engineers need specific tools such as the ones defined for the design of dowelled joints. Hopefully, the most important outcomes of existing (and ongoing) research will be integrated into the revised version of Eurocode 5.

\section{References}

[1] Descamps T., Léoskool L., Laplume D., Van Parys L., Aira J.R., Sensitivity of timber hyperstatic frames to the stiffness of step and ridge joints. World Conference on Timber Engineering, Quebec, Canada, 2014.

[2] Parisi M., Piazza M., Mechanics of plain and retrofitted traditional timber connections. Journal of Structural Engineering, 126(12):1395-1403, 2000.

[3] Branco J.M., Piazza M., Cruz P.J.S., Experimental evaluation of different strengthening techniques of traditional timber connections. Engineering Structures. 33 (8), 2011, 22592270. 2011, http://hdl.handle.net/1822/13592

[4] Descamps T., Noël J., Semi-rigid analysis of old timber frames: definition of equivalent springs for joints modeling. Enhancement of the method, numerical and experimental validation. International Review of Mechanical Engineering. Volume 3, Number 2, March 2009, pp 230-239, 2009.

[5] Gerner M., Les assemblages des ossatures et charpentes en bois, Ed. Eyrolles, 190 pages, 2012.

[6] Sobon J.A., Historic American timber Joinery, a graphic guide. Published by the Timber Framers Guild, PO Box 60, Becket, MA 01223, 56 pages, 2012.

[7] KiyosiSeike, The Art of Japaneese Joinery. 128 pages

[8] Meisel A., Moosbrugger T., Schickhofer G., Survey and Realistic Modelling of Ancient Austrian Roof Structures. In Proc. of Conservation of Heritage Structure (CSHM-3), Ottawa, Canada, 2010

[9] SIA 265: Constructions en Bois. Swiss society of engineers and architects, 2003

[10] Hewett C.A., English Historic Carpentry. London \&Chichester: Phillimore\& Co. Ltd., 1980, p. 270 . 
[11] Hirst E., Brett A., Thomson A. Walker P., Harris R., The Structural Performance of Traditional Oak Tension \& Scarf Joints, 10th World Conference on Timber Engineering, Miyazaki, Japan, 2008.

[12] Thelandersson, S., Larsen, H. J. Timber Engineering. Chichester: John Wiley \& Sons Ltd., 2003, p.346.

[13] Larsen H., Jensen J., Influence of semi-rigidity of joints on the behaviour of timber structures. Prog. Struct. Engng Mater., 2:2767-2778, 2000.

[14] Candelpergher L., Sperimentazione, modellazionenumerica e caratterizzazionesinteticadelcomportamento di collegamentiligneitradizionali con elementimetallici. Master's thesis, UniversitàdegliStudi di Trento, 1999.

[15] Palma P., Cruz H., Mechanical behaviour of traditional timber carpentry joints in service conditions - results of monotonic tests. In From material to Structure - Mechanical behaviour and failures of the timber structures, XVI International Symposium, ICOMOS IWC, 2007.

[16] Uzielli L., Il manuale del Legno Strutturale, Vol IV - Interventi sulle strutture. Mancosu, Rome, Italy, in Italian, 2004

[17] Drdácký M., Wald F., Sokol, Z., Sensitivity of historic timber structures to their joint response. Madrid, 1999.

[18] Descamps T., Lambion J., Laplume D. (2006), Timber Structures: Rotational stiffness of carpentry joints. World Conference on Timber Engineering, Portland, USA, 2006

[19] Komatsu K., Kitamori A., Jung K. and Mori T., Estimation of The Mechanical Properties of Mud Shear Walls Subjecting to Lateral Shear Force, In Proc. of the $11^{\text {th }}$ Int. Conference on Non-conventional Materials and Technologies, 6-9 September, Bath, UK, 2009.

[20] Chang W.-S., Hsu M.-F., Komatsu K., Rotational performance of traditional Nuki joints with gap I: theory and verification. Journal of Wood Sciences, 52:58-62, 2006.

[21] Wald F., Mares Z., Sokol M., Drdácký F, Component Method for Historical Timber Joints. in The Paramount Role of Joints into the Reliable Response of Structures. vol. 4, C. C. Baniotopoulos and F. Wald, Eds., ed: Springer Netherlands, 2000, pp. 417-424.

[22] UNI 11138, Cultural heritage - Wooden artefacts - Building load bearing structures - Criteria for the preliminary evaluation, the design and the execution of works. UNI Milano, 2004.

[23] Aman R., West H., Cormier D. An evaluation of loose tenon joint strength. For Prod J, 58(3):61-642, 2008.

[24] Judd J., Fonseca F., Walker C., Thorley P., Tensile strength of varied-angle mortise and tenon connections in timber frames. J Struct Eng 137(5):636-644, 2012.

[25] Likos E., Haviarova E., Eckelman C., Erdil Y., Ozcifci A., Effect of tenon geometry, grain orientation, and shoulder on bending moment capacity and moment rotation characteristics of mortise and tenon joints. Wood Fiber Sci 44(4):1-8, 2012.

[26] Kock H., Eisenhut L., Seim W., Multi-mode failure of form-fitting timber connections Experimentaland numerical studies on the tapered tenon joint. Engineering Structures 48 (2013) 727-738. 
[27] Feio A.O., Lourenço P.B., Machado J.S., Testing and modeling of a traditional timber mortise and tenon joint. Materials and Structures. 47:213-225, 2014

[28] Götz K.-H., Hoor D., Möhler K., Natterer J., Construire en Bois - Choisir, concevoir, realiser. Presses Polytechniques et Universitaires Romandes, Lausanne, Switzerland, 1993.

[29] DIN 1052, Entwurf, Berechnung und Bemessung von Holzbauwerk. Allgemeine bemessungsregeln und bemessungsregeln fur den hochbau, 2004.

[30] C.T.E., Documento Básico SEM. Seguridad estructural - Estructuras de madera. A código técnico de la edificación, ministerio de vivienda, 2006

[31] EN 1998-1:2004. Eurocode 8: Design of structures for earthquake resistance- Part 1: General rules. Brussels, CEN, European Committee for Standardization, 2004

[32] Branco J.M. 2008, Influence of the joints stiffness in the monotonic and cyclic behaviour of traditional timber trusses. Assessment of the efficacy of different strengthening techniques. $P h D$ thesis, University of Minho and University of Trento, 2008

[33] Branco J, Cruz P, Varum H, Piazza M., Portuguese traditional timber trusses. Static and dynamic behaviour. Technical Report E-19/05, Guimarães, Portugal. in Portuguese, 2005

[34] Bléron L., Lathuillière D., Descamps T., Reinforcement of dowel type connections, State of the art report on reinforcement of timber structures, COST Action FP1101, 2014.

[35] Yeomans D., The Repair of Historic Timber Structures. London: Thomas Telford Publishing, 2003, p. 147-150.

[36] EN 1995-1:2005,Eurocode 5: Design of timber structures - Part 1-1: Common rules and rules for buildings.Brussels, CEN, European Committee for Standardization, 2005

[37] DIN EN 1995-1:2005,NCI NA 6.8.3. National German Annex to Eurocode 5: Design of timber structures - Part 1-1: Common rules and rules for buildings.Brussels, CEN, European Committee for Standardization, 2005 